Lor publication in the Proceedings of the Second International Conference on the Basic and Applied Chemistry of f-Transition (Lanthanide and Actinide) and Related Elements, Lisbon, Portugal, April 6-10, 1987]

CONF-870443--1

DE87 008782

\title{
POSSIBLE STABILIZATION OF THE TETRAVALENT OXIDATION STATE OF BERKELIUM AND CALIFORNIUM IN ACETONITRILE WITH TRIPHENYLARSINE OXIDE*
}

Gerard F. Paynet and Joseph R. Peterson

\author{
Department of Chemistry \\ University of Tennessee \\ Knoxville, TN 37996-1600 USA
}

and

Transurasium Research Laboratory (Chemistry Division)

Oak Ridge National Laboratory

Oak Ridge, TN 37831-6375 USA

\section{DISCLAIMER}

\begin{abstract}
This report was prepared as an account of work sponsored by an agency of the United States Government. Neither the United States Government nor any agency thereof, nor any of their employees, makes any warranty, express or implied, or assumes any legal liability or responsibility for the accuracy, completeness, or usefulness of any information, apparatus, product, or process disclosed, or represents that its use would not infringe privately owned rights. Reference herein to any specific commercial product, process, or service by trade name, trademark, manufacturer, or otherwise does not necessarily constitute or imply its endorsement, recommendation, or favoring by the United States Government or any agency thereof. The views and opinions of authors expressed herein do not necessarily state or reflect those of the United States Government or any agency thereof.
\end{abstract}

\footnotetext{
*Research sponsored by the Division of Chemical Sciences, U.S. Department of Energy under contracts DE-AS05-76ER04447 with The University of Tennessee, Knoxville and DE-AC05-840R21400 with Martin Marietta Energy Systems, Inc.

tAuthor to whom correspondence should be addressed at ORNL.
} 
Introduction

Both nonaqueous solvents [1] and strongly complexing ligands $[2,3]$ have been used to stabilize the tetravalent (IV) state of certain lanthanides and actinides (lanacts) $[4,5]$. We have chemically oxidized selected lanact(III) nitrates and chlorides to the IV state in acetonitrile $\left(\mathrm{CH}_{3} \mathrm{CN}\right)$ in the presence of triphenylarsine oxide (TPAs0) $[6,7]$. Once a M(IV) nitrate.nTPAsO complex is formed, the bulky ligands, which apparently surround the metal ion [8], seem to prevent its further reaction with reducing agents both in solution and in the solid state. The chloride complexes, on the other hand, are only stable in the $\mathrm{CH}_{3} \mathrm{CN}$ solution. In the solid state these complexes are probably

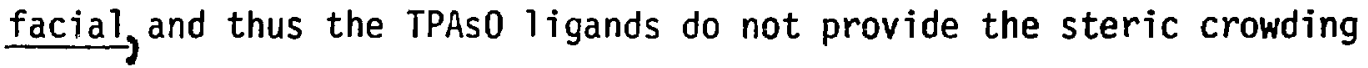
necessary for stabilization of the M(IV) species [8]. These techniques were proven successful $[6,7]$ in stabilizing $\mathrm{Ce}(\mathrm{IV}), \operatorname{Pr}(\mathrm{IV}), \mathrm{Tb}(\mathrm{IV})$, and Am(IV) before they were applied to BK, whose (IV)/(III) potential is very close to that of Ce. From the beta decay of Bk-249 $\left(t_{\frac{1}{2}}=320 \mathrm{~d}\right.$; $E_{\max }=0.126 \mathrm{MeV}$ ) it was anticipated that the corresponding Cf(IV) species might be obtained, as has been the case in the solid state halides of Bk-249 [9]. We sumnarize briefly our previous lanthanide results and report the present status of the decay studies to produce a Cf(IV) -nTPAsO complex from a Bk(IV) •nTPAsO complex. 
Experimenta 1

Reagent grade acetonitrile was dried over $\mathrm{K}_{2} \mathrm{CO}_{3}$ and stored over molecular sieves. Lanthanide(III) salts and TPAs0 were obtained from commercial sources and used without further purification. Am-243 and Bk-249 were obtained from the transplutonium element production facility at the Oak Ridge National Laboratory and purified by standard ion-exchange techniques [10]. Details of the preparations of the tetravalent lanthanide and Am complexes with TPAs0 are given elsewhere $[6,7] .250 \mu \mathrm{g}$ of purified $\mathrm{BK}$ (III) in $2 \mathrm{M} \mathrm{HNO}_{3}$ was taken to dryness and then redissolved in conc. $\mathrm{HClO}_{4}$. This latter operation was repeated, and once again the whole was dried and then dissolved in $\mathrm{CH}_{3} \mathrm{CN}(2 \mathrm{~mL})$. Another $250 \mu \mathrm{g}$ of $\mathrm{Bk}$ (III) in $2 \mathrm{M} \mathrm{HiNO}_{3}$ was taken to dryness and dissolved in $\mathrm{CH}_{3} \mathrm{CN}(2 \mathrm{~mL})$. The effects of heating the solutions to $70-80^{\circ} \mathrm{C}$ with and without concurrent ozonolysis, along with the influence of the TPAsC (usually 2-3 moles per mole of metal), were investigated. Solids were recovered from the solutions by evaporation of the solvent, dissolution of the residue in acetore and precipitation of solid upon addition of pentane. The solids were loaded into glass capillary tubes for study via X-ray powder diffraction and microscale absorption spectrophotometry [11]. Absorption spectra of the complexes in $\mathrm{CH}_{3} \mathrm{CN}$ solution in $1-\mathrm{cm}$ cuvettes fitted with quartz spacers $\left(\sim 10^{-4} \mathrm{M} B K\right)$ were obtained with a Cary Model 14-M spectrophotometer. 
Results and Discussion

$\mathrm{Ce}$ (III), $\operatorname{Pr}$ (III), and $\mathrm{Tb}$ (III) nitrates in $\mathrm{CH}_{3} \mathrm{CN}$ at $70^{\circ} \mathrm{C}$ were subjected to ozonolysis $(\leq 24 \mathrm{~h})$ in the presence of TPAs0 to stabilize the IV state of these metal ions [6]. Separate $\mathrm{CH}_{3} \mathrm{CN}$ solutions of the nitrates and chlorides of $\mathrm{Ce}(\mathrm{III})$ and $\mathrm{Am}$ (III) in the presence of TPAsO were bubbled with air/oxygen at $70^{\circ} \mathrm{C}$ to achieve at least partial oxidation of the metal ions [7]. In both studies absorption spectrophotometry and cyclic voltammetry were used to determine that metal ion oxidation (to the IV state) had indeed occurred. Solids of most of these M(IV) complexes were obtained. The nitrates were stable to both air and moisture, in contrast to the $\mathrm{Ce}$ (IV) chloride complex which reduced to Ce(III) over a period of days.

In the case of BK(III), the oxidation of both nitrate and perchlorate complexes was investigated. Heating the respective $\mathrm{CH}_{3} \mathrm{CN}$ solutions at $80^{\circ} \mathrm{C}$ or subjecting them to ozonolysis for $15 \mathrm{~min}$ at room temperature, both in the absence of TPASO, produced no apparent oxidation based on visual and spectrophotometric analysis. However, upon addition of TPAsO to the ozonized $\mathrm{BK}$ (III) nitrate in $\mathrm{CH}_{3} \mathrm{CN}$ solution it room temperature and to the ozonized $\mathrm{BK}$ (III) perchlorate in $\mathrm{CH}_{3} \mathrm{CN}$ solution at $70^{\circ} \mathrm{C}$, the solutions became pale yellow. Over a short time the nitrate solution became intensely yellow colored, whereas the perchlorate solution became first light brown and then brown. Both solutions were evaporated to dryness, taken up in acetone, and yielded recoverable precipitates upon addition of pentane. Unfortunately, 
absorption spectrum significantly different from the standard quartz capillary blank established for our single-beam microscope spectrophotometer [11].

In another set of BK(III) oxidation experiments, a pale yellow solution resulted from heating the $\mathrm{BK}$ (III) nitrate in $\mathrm{CH}_{3} \mathrm{CN}$ solution to $80^{\circ} \mathrm{C}$ but only after TPAsO was added to the solution. Following ozonolysis of this solution for $15 \min$ at $70^{\circ} \mathrm{C}$, the solution was orange/yellow. Starting with the $\mathrm{BK}$ (III) perchlorate in $\mathrm{CH}_{3} \mathrm{CN}$ solution, no changes were observed visually or spectrophotometrically following heating to $80^{\circ} \mathrm{C}$, cooling and adding TPAs $\mathrm{O}$, and subsequent reheating. During the course of a 15 min ozonolysis at $270^{\circ} \mathrm{C}$, this same solution became pale yellow, then light brown, and finally brown. After standing for several days, this solution became intensely yellow-orange colored. The solution absorption spectra obtained from the ozonized BK(III) nitrate and perchlorate complexes exhibited a UV cut-off of transmitted light around $300 \mathrm{~nm}$ when the complexes were $298 \% \mathrm{BK}$. Over time, as Cf grew into the solution, this UV cut-off moved more into the visible wavelength range, e.g., around $425 \mathrm{~nm}$ when the complexes were $\sim 67 \% \mathrm{Bk}$. We associate this intense (allowed) absorption with the ligand-to-metal charge transfer (LMCT) banoss of both BK(IV) and CF(IV), with that of the ingrowing $C f(I V)$ occurring at longer wavelength (lower energy) in accord with its lesser stability relative to that of $5 f^{7}$-stabilized $\mathrm{Bk}$ (IV). It should be noted that our solution absorption spectra did not exhibit any of the characteristic, although weak (Laporte forbidden), $f \rightarrow f$ transitions in BK(III), Cf(III), BK(IV), and Cf(IV). This latter fact is not surprising when one considers that the molar extinction coefficients of the $f \rightarrow f$ transitions are probably $\leqq 20$ and the total 
actinide ion concentration is about $10^{-4} \mathrm{M}$. The limited availability of $B k-249$ in this work precluded an intense search for these $f \rightarrow f$ absorption bands.

Very recently, about a year following the initial preparation of these $\mathrm{BK}$ (IV) complexes ( $43 \% \mathrm{Bk} ; 57 \% \mathrm{Cf}$ ), solution absorption spectra of the nitrate and perchlorate complexes were again recorded. The UV cut-off of transmitted light, which we have attributed to $C f(I V)$, is still the only spectral feature present. No $f \rightarrow f$ absorption bands were observed.

In conclusion, it appears that we may have prepared BK(IV) nitrate-nTPAs 0 and BK(IV) perchlorate-nTPAs 0 complexes which formed the corresponding $C F(I V)$ complexes through the beta decay of Bk-249. Definitive proof should come from similar experiments with quantities of Bk-249 large enough to allow spectrophotometric detection of the characteristic $f \rightarrow f$ transitions in these berkelium and californium species. It is clear, however, that TPAsO and acetonitrile can play a pivotal role in the stabilization of lanact(IV) species. 
Acknowledgements

The authors are indebted for the use of Bk-249 in this work to the Division of Chemical Sciences, Office of Basic Energy Sciences, U.S. Department of Energy through the transplutonium element production facilities at the Oak Ridge National Laboratory and to Dr. Richard G. Haire (ORNL Chemistry Division) for his careful pruification of the Bk(III). This research was sponsored by the Division of Chemical Sciences, U.S. Department of Energy under contracts DE-AS05-76ER04447 with the University of Tennessee, Knoxville, and DE-ACO5-840R21400 with Martin Marietta Energy Systems, Inc. 


\section{References}

1 P. G. Varlashkin and J. R. Peterson, J. Less-Common Metals, 94, 333 (1983).

2 D. E. Hobart, K. Samhoun, 1. P. Young, V. E. Norve11, G. Mamantov, and J. R. Peterson, Inorg. Nuc1. Chem. Letters, 16, 321 (1980).

3 D. E. Hobart, K. Samhoun, and J. R. Peterson, Radiochim. Acta, 31, 139 (1982).

4 K. W. Bagnal1, A. M. Deane, T. L. Markin, P. S. Robinson, and M. A. A. Stewart, J. Chem. Soc., 1611 (1961).

5 B. W. Fitzsimmons, P. Gans, B. C. Smith, and M. A. Wasse1, Chem. Ind: London, 1698 (1965).

6 G. F. Payne and J. R. Peterson, J. Less-Common Metals, 126, 371 (1986).

7 G. F. Payne and J. R. Peterson, Radiochim. Acta, 39, 155 (1986).

8 R. R. Ryan, E. M. Larson, G. F. Payne, and J. R. Peterson, Inorg. Chim. Acta (in press).

9 J. R. Peterson, J. P. Young, D. D. Ensor, and R. G. Haire, Inorg. Chem., 25, 3779 (1985) and references therein.

10 R. D. Baybarz, J. B. Knauer, and P. B. Orr, Oak Ridge National Laboratory Document ORNL-4672 (1973).

11 J. P. Young, R. G. Haire, R. L. Fellows, and J. R. Peterson, J. Radioanal. Chem, 43,479 (1978). 